\title{
EL GOLPE QUE NO FUE. LA ÚLTIMA CRISIS ESTATAL BOLIVIANA Y LOS LÍMITES DEL CONCEPTO DE GOLPE DE ESTADO
}

\section{The coup that wasn't. The last Bolivian state crisis and the limits of the concept of Coup d'État}

\author{
FRANZ XAVIER BARRIOS SUVELZA \\ Universidad de Erfurt \\ franz.barrios_suvelza@uni-erfurt.de
}

Cómo citar/Citation

Barrios Suvelza, F. X. (2021).

El golpe que no fue. La última crisis estatal boliviana

y los límites del concepto de golpe de Estado.

Revista de Estudios Políticos, 191, 185-214.

doi: https://doi.org/10.18042/cepc/rep.191.07

\section{Resumen}

A raíz de los acontecimientos en Bolivia referidos a la renuncia del Presidente Evo Morales a fines de 2019, se ha desatado una polémica internacional sobre si lo sucedido puede catalogarse como un golpe de Estado. El artículo devela por qué, independientemente de las inclinaciones subjetivas del observador, no cabe calificar lo sucedido en Bolivia como un golpe de Estado. Se revela que el insatisfactorio desempeño descriptivo de dichos acontecimientos es atribuible no sólo a cierta desidia analítica, sino a que el concepto mismo de golpe de Estado puede haber encontrado sus propios límites cognitivos. Para superar estos límites el artículo propone ampliar el esquema convencional trifásico (blanco/perpetrador/táctica) de abordaje conceptual de golpe de Estado mediante la incorporación de la variable del orden legal parcial referido al regimen político. Como un golpe supone por definición el quebrantamiento de dicho orden, se sugiere usar el concepto de reencauzamiento de Estado en caso de que la remoción anormal de un mandatario coincida con que dicho orden haya estado quebrado de antemano. 


\section{Palabras clave}

Crisis constitucional; golpe de Estado; autoritarismo; régimen político; teoría del Estado; constitucionalismo latinoamericano.

\section{Abstract}

In the light of the events in Bolivia referring to the ousting of President Morales towards the end of 2019, a huge international polemic emerged as to whether the accurate description of these events was a coup d'État. This article concludes that, independently of personal inclinations, to opt for the coup d'État variant is misleading. The analytical problems faced with the Bolivian case seem to stem not only from the hasty way in which scholars dealt with the facts behind the events, but also from the fact that the very coup concept may have reached its own cognitive limits. In order to overcome these limits the article expands the conventional threefold scheme (target/ perpetrators/tactic) for defining a coup by adding the variable of the partial legal order concerning the political regime of the country. Given that definitionally the concept of a coup d'État implies the breaking of this order, it is argued to use the concept of restauration of the state instead of coup, if the anormal disruption of a president's period coincides with the fact that the mentioned order was already broken.

\section{Keywords}

Constitutional crisis; coup d'État; authoritarianism; political regime; state theory; Latin American constitutionalism. 


\section{SUMARIO}

I. INTRODUCCIÓN. II. BREVE CONTEXTUALIZACIÓN DEL CASO BOLIVIANO: 1. Divergentes posiciones sobre si hubo golpe. III. LOS DILEMAS TEÓRICO-CONCEPTUALES DEL CONCEPTO DE GOLPE DE ESTADO: 1. Una primera aproximación al concepto de orden legal parcial. 2. Las definiciones convencionales de golpe y el OLP. 3. Hacia una extensión de los atributos que definen golpe de Estado. 4. Distinguir revueltas de palacio y precisar la composición del OLP. IV. DEL GOLPE DE ESTADO AL REENCAUZAMIENTO DE ESTADO: 1. Naturaleza del reencauzamiento de Estado y sus parámetros de plausibilidad. 2. Vías alternativas a la idea del reencauzamiento de Estado. 3. El reencauzamiento de Estado si se sustituyó el orden quebrado. 4. El reencauzamiento de Estado cuando son órganos legales los que participan del quiebre. 5. El reencauzamiento de Estado cuando pesa la inercia conceptual o se aduce politización del concepto. Indiferencia frente a autodescripciones y problemas de aplicabilidad a lo autocrático. V. LA APLICACIÓN DEL NUEVO CONCEPTO AL CASO CONCRETO: 1. Bolivia como referente del reencauzamiento de Estado. 2. Pruebas adicionales de que no hubo golpe. 3. La prueba final. VI. CONCLUSIONES. BibLIOgrafía.

\section{INTRODUCCIÓN'}

Si bien los golpes de Estado se han vuelto una técnica menos usada para la disrupción anómala de un mandatario, ello no ha impedido que el término de golpe se expanda. Esto ha sido concomitante a un estiramiento conceptual con costos cognitivos y políticos (Marsteintredet y Malamud, 2019). La deposición de Evo Morales a fines de 2019 en Bolivia ha confirmado el temor de Marsteintredet y Malamud de que los analistas siguen propensos a usar el término golpe casi por reflejo. Adjetivar el sustantivo golpe tampoco ha mejorado su capacidad descriptiva (ibid.: 17). Si bien el diagnóstico de estos autores es acertado, su trabajo ha dejado cabos sueltos debido a que respetan determinados convencionalismos en el tratamiento del concepto de golpe de Estado. Tomando como ilustración el caso boliviano, este artículo busca avanzar en la crítica al relajamiento de dicho concepto. Para ello, se opta por la estrategia de precisión que es una de las tres que Collier y Levitsky (1997: 437) proponen contra el estiramiento

1 El autor agradece a los evaluadores de la REP, a Jonas Wolff por facilitar a tiempo su último trabajo sobre el tema aquí tratado y a Isabel Mercado por dar acceso a una fuente bibliográfica relevante. 
conceptual. Eso desemboca en expandir, con la variable del orden legal parcial (OLP), la estructura trifásica (perpetradores/objetivo/táctica) corrientemente usada para definir golpe (Marsteintredet y Malamud, 2019: 2, 8, 9). Este OLP apunta al conjunto de reglas que regulan el régimen político, especialmente la salida y entrada al puesto máximo del Ejecutivo. El OLP no solo ha sido una variable subteorizada, sino subvaluada en la definición de golpe de Estado. Aclarando su naturaleza y jerarquizándola en la conceptualización de golpe, sienta las bases para entrever por qué no cuadra describir como golpe lo que pasó en Bolivia a fines del 2019.

Sobre esta base se introduce seguidamente un concepto que evite el sobreuso del término golpe y describa mejor experiencias como la boliviana. Si bien un nuevo término tiene riesgos, sucede que "nuevas formas [...] de remociones de mandato» (ibid.: 16, itálicas mías) no siempre se dejan capturar con conceptos establecidos. Hay autores que cuestionan si el concepto de golpe sigue siendo apropiado para describir cualquier "cambio no agendado de gobierno" (Pitts et al., 2016: 344). Si se llegara a la conclusión de que un golpe, además de implicar una remoción ilegal de un mandatario, conlleva la quiebra del más genérico OLP, ¿qué sentido tiene llamar golpe a una remoción que además de ser probablemente legal no encontró un OLP que quebrar debido a que este pudo haber sido quebrado antes que la remoción tuviera lugar? En tal caso, se sugiere emplear el concepto de reencauzamiento de Estado en lugar del de golpe de Estado. O si se prefiere el léxico clásico, se hablaría de un remboîtement d'État en lugar de un coup d'État.

Tanto la expansión de atributos para definir golpe, como la introducción de un concepto para evitar el sobreuso del concepto de golpe, divergen de lo que viene elaborando la academia, pero mantienen vínculos con ella para garantizar la acumulación de conocimiento. Más allá de un mejor diagnóstico del caso analizado, un rédito general del ejercicio propuesto redunda en un incremento de la precisión del concepto de golpe y en obstaculizar su uso político o ideológico (Marsteintredet y Malamud, 2019: 16). El artículo comienza recapitulando los acontecimientos en Bolivia. Luego se sustenta conceptualmente tanto la dilucidación de los rasgos centrales del OLP, como la estrategia de una expansión en las variables definitorias de golpe. Seguidamente se introduce el concepto reencauzamiento de Estado como alternativo a golpe para describir peculiares realidades. La penúltima sección vuelve al caso boliviano para probar el nuevo concepto. El artículo cierra con conclusiones.

2 Se toma este término de Kelsen (1949: 304, 373), usado originalmente para describir la diferenciación territorial del orden legal del Estado. El Estado contiene varios órdenes legales parciales. Aquí, el OLP es aquel referido al régimen político. 


\section{BREVE CONTEXTUALIZACIÓN DEL CASO BOLIVIANO}

La renuncia de Evo Morales el 10 de noviembre de 2019 representa una hendidura para Bolivia. Baste recordar que luego que este asumiera el poder en 2006, presentó la reforma total constitucional consumada en 2009, que él patrocinó, como el cierre de la república nacida en 1825 y el nacimiento de una nueva entidad ${ }^{3}$. Esta aspiración se correspondía con un entusiasmo rupturista que Bolivia vivía en esos días y que se tradujo en apoyo para Evo Morales de inéditas mayorías electorales en la historia del país. ${ }^{4}$ En una entrevista que él diera tiempo después de asumir la presidencia, sostuvo que su movimiento político se quedaría quinientos años, como lo habían hecho las élites previas 5 . Luego de catorce años de su ascenso al poder este plan se ha truncado.

La interrupción del mandato de Evo Morales estuvo mediatamente precedida por una pérdida de legitimidad de su Gobierno por corrupción, agotamiento de ingresos fiscales, enfrentamientos con bases indígenas, daño ecológico, un campo competitivo inclinado a favor del oficialismo y un entorno regional políticamente desfavorable (Wolff, 2020; Lehoucq, 2020; Farthing, 2020). Inmediatamente, dicha interrupción estuvo precedida por las cuestionadas elecciones del 20 octubre de 2019, en las que, según datos oficiales, Evo Morales habría obtenido suficientes votos para evitar el balotaje $^{6}$. La interrupción abrupta del conteo de votos el día de la elección (Peralta, 2019: 32) fue el detonante que movilizó a masas ciudadanas durante veintiún días (Carrillo, 2019: 43) por presumirse un fraude. Ante estas presiones, y luego de que la policía nacional se insubordinara primero en la región de Cochabamba el 8 de noviembre de 2019 (Romero, 2019: 77), Evo Morales se abrió a concesiones que, sin embargo, no guardaban paso con el ritmo de radicalización. Ante la inmanejabilidad de las protestas, Evo Morales accedió el 31 de octubre (García, 2019: 88) a que la Organización de Estados Americanos (OEA), cuyos veedores ya habían expresado dudas el mismo día de la elección

3 Ver el preámbulo de la nueva Constitución boliviana aprobada por referéndum el 25 de enero de 2009. Para una valoración desde la perspectiva del nuevo constitucionalismo latinoamericano, véase Barrios-Suvelza (2018).

$4 \quad 53,74 \%$ en $2005 ; 63,91 \%$ en 2009; y 61,01\% en 2014. Disponible en: https://bit. ly/3s 1 MIEE.

5 «Evo pide quinientos años de movimientos sociales». El Deber, 27-12-2016. Disponible en: https://bit.ly/2NDoRfo.

6 Los resultados oficiales finales fueron de 47,08\% para Morales y 36,51\% para Mesa. Disponible en: https://bit.ly/3bf1JvX. Con lo cual tanto el mínimo de votos (40\%) como la mínima distancia entre primero y segundo (10\%) exigidos por el art. 166/1 de la Constitución boliviana se alcanzaban, librando a Evo Morales del balotaje. 
sobre el conteo de votos (Organization of American States, 2019a), hiciera una auditoria sobre el acto electoral. Según Evo Morales, ese informe debió ser entregado el 13 noviembre, pero fue sorprendido, según su propio relato (Morales, 2020: 40), por su publicación el día domingo 10. En dicha auditoría (Organization of American States, 2019b) se habla de irregularidades del proceso electoral y su publicación antecedió ese domingo la conferencia de prensa en la que Evo Morales dimitió?.

\section{DIVERGENTES POSICIONES SOBRE SI HUBO GOLPE}

En esa conferencia Evo Morales mencionó que fue víctima de un "golpe cívico» ${ }^{8}$, omitiendo mencionar lo militar. La cuestión de si hubo golpe se convirtió en debate internacional. Tanto quienes son escépticos sobre la versión del golpe o la niegan (Wolff, 2020: 177; Lehoucq, 2020: 140; Barrios-Suvelza, 2019), como los que la apoyan (Natanson, 2019; Shifter, 2019; Farthing, 2020: 5, 12) presentan argumentos plausibles. Quienes rechazan la versión del golpe (p. ej. Lehoucq, pero no así Barrios-Suvelza), pero también quienes la apoyan, suelen centrarse en el rol de los militares. Quienes se inclinan por la hipótesis de que no hubo golpe «militar»" subrayan que ningún militar asumió el poder (p.ej. Lehoucq, 2020: 132), mientras que quienes manejan la hipótesis del golpe, lo hacen basados en que Evo Morales renunció solo después del pronunciamiento militar que le sugirió hacerse a un lado (p. ej. Levitsky, 2019). Las protestas que antecedieron la renuncia de Evo Morales fueron masivas, abarcaron todo el país y fueron soportadas por sectores urbanos, clases medias (Lehoucq, 2020: 137, 138) y sectores populares (Wolff, 2020: 165; Farthing, 2020: 5). Estas protestas han sido calificadas como una "rebelión ciudadana» que condujo a una renuncia voluntaria (Lehoucq, 2020: 131), descartándose así que la causa de esta hubiera sido una acción militar y que el golpe fuera el adecuado descriptor (ibid.: 140). Entre quienes sostienen la versión del golpe militar, está quien admite que es posible que los militares no organizaran premeditadamente la caída, pero que «le dieron el empujón final» (Natanson, 2019). Otros encuadran su argumento en un supuesto resurgimiento de la influencia militar en la política

7 Si hubo o no fraude sigue siendo motivo de polémica. Para un análisis sistemático, véase Wolff (2020).

8 «Cronología de la renuncia de Evo Morales». El Tiempo, 10-11-2019. Disponible en: https://bit.ly/2ZqnJ1k.

9 Parece plausible asumir que Lehoucq rechaza el golpe de Estado como tal, aunque diga que no hubo golpe «militar». 
latinoamericana valorando lo sucedido en Bolivia como una corroboración (Levitsky y Murillo, 2019; Natanson, 2019).

En esta polémica hubo quien unió lo académico con un mandato moral de análisis. Así, Levitsky y Murillo (2019), luego de diagnosticar que lo de Bolivia fue un golpe, advierten: «Si los Gobiernos extranjeros eligen un bando en los conflictos de esta región y toleran golpes de Estado que favorecen a sus aliados ideológicos en vez de defender la democracia de manera constante, motivarán un regreso a la violencia y la inestabilidad que los latinoamericanos tanto han luchado por erradicar». En otras palabras, si Gobiernos guiados por inclinaciones ideológicas apoyan la interrupción del mandato de Evo Morales a sabiendas de que se trató de un golpe, le harían un flaco favor a la democracia en esta región. Así puestas las cosas, la apuesta por la democracia obliga a tomar como la verdad la versión de golpe de Estado. Si bien estas advertencias pueden ser de algún interés, no hay desperdicio en cuestionarse si lo sucedido fue un golpe, sin que ello implique alentar analíticamente la violencia en América Latina.

\section{LOS DILEMAS TEÓRICO-CONCEPTUALES DEL CONCEPTO DE GOLPE DE ESTADO}

\section{UNA PRIMERA APROXIMACIÓN AL CONCEPTO DE ORDEN LEGAL PARCIAL}

Lo sucedido en Bolivia revela límites del concepto de golpe de Estado. Indagadas las premisas teóricas que sustentan este concepto y averiguada la medida en que ellas cubren lo sucedido, revela que hablar de golpe de Estado en este caso no convence. Si bien un golpe se patentiza en la interrupción irregular del mandato de un presidente, alude al mismo tiempo a la ruptura del orden legal dirigido a regular la conformación de la dirección política de un Estado. Esta ruptura se asemeja a lo que Bermeo (2016: 6), al referirse al democratic backsliding, llamó un "cambio radical y rápido a través de un rango amplio de instituciones» que desemboca en un «derrumbe completo» y conduce "hacia regímenes que son inequívocamente diferentes». Se puede llamar a este conjunto de reglas especiales diseñadas para regular este proceso - incluyendo las de naturaleza constitucional y abarcando las fases previas y posteriores al acto electoral mismo- un orden legal parcial (OLP). Los académicos no siempre han considerado esta faceta en la definición de golpe y cuando lo han hecho suele pasar que se vayan a los extremos. $\mathrm{O}$ ven al golpe como variante de revolución y, por tanto, como acto de «anulación del orden legal de la comunidad» (Kelsen, 1949: 117), o lo ven como fuente del reemplazo de un «reino 
legal» por otro diferente, del «mismo modo que los eventos sacaron en 1789 a Francia de la monarquía absoluta hacia la república»(Green, 2005: 335). Frente a la posición extrema de Kelsen (1949: 118, mis itálicas) de ver tras un golpe el derrumbe del «orden legal entero», Mahmud (1994: 107) sostiene que los "golpes en sociedades postcoloniales [...] no aspiran a la destrucción del orden legal entero, sino solo buscan la usurpación de los puestos políticos». Mahmud acierta al evitar hablar del orden legal «entero» como blanco del golpe y yerra en reducirlo a un acto de usurpación de cargos. Lo que un golpe quiebra es lo que Kelsen (1949: 117, mis itálicas) llamara «ciertas normas de significación política preponderante», lo cual se acerca a lo que aquí se llama un OLP, aunque tal golpe, como Kelsen insiste, deje «gran parte del viejo orden legal como válido». Mahmud (1994: 129, mis itálicas), cerrando su polémica con Kelsen (1949: 117) y su idea de que el golpe derrumba «la constitución», concluye que un golpe «típicamente suprime solo aquella parte de la constitución que trata de los órganos políticos del Estado; el resto de la constitución y el sistema legal mayor es expresamente dejado en su lugar». Si un golpe de Estado entonces ha de quebrar un OLP — que es menos que toda la constitución pero más que una mera usurpación de cargos—, ¿qué sentido tendría usar este concepto para la interrupción irregular del mandato de Evo Morales si ella coincidió con que el OLP boliviano estaba quebrado de antemano? Parece tener sentido buscar un concepto que, al combinar la interrupción irregular del mandato de un presidente con un OLP previamente quebrado, transmita sin rodeos el advenimiento de un potencial proceso de reparación de un OLP de antemano quebrado. En vez de un golpe de Estado, se habrá producido un reencauzamiento del mismo.

\section{LAS DEFINICIONES CONVENCIONALES DE GOLPE Y EL ORDEN LEGAL PARCIAL}

Si bien no es raro que el sentido común conecte la idea de golpe con el quebrantamiento de un orden legal, llama la atención que las definiciones convencionales o no lo mencionen como parámetro decisivo (Rapoport, 1966: 60; Huntington, 1968: 218; Luttwak, 1969: 24; Martínez, 2014: 203; Aksoy et al., 2015: 438; Svolik, 2015: 730; Bermeo, 2016: 6; Marshall y Marshall, 2016: 1), o lo traten pendularmente al proponerse que con el golpe se ambiciona una "transformación profunda de las reglas de juego político" y se afirme seguidamente que el golpe «busca, pura y simplemente, la obtención del poder o la anulación de un adversario político» (González, 2001: 91), aunque, ocasionalmente, este pueda incluso llevar a un «cambio radical en la naturaleza del régimen político» (ibid.: 92). Una de las más expandidas definiciones de golpe no menciona al OLP en la lista de parámetros definitorios 
(Powell y Thyne, 2011: 250). En ella entran elementos como quién es el que sufre la remoción, cuál es la naturaleza de los perpetradores del golpe y qué táctica ha sido empleada para remover al mandatario. Se complementa que el golpe debe ser algo abierto y no supuesto y que, cuando sea exitoso, se tomará en cuenta un tiempo mínimo de ocupación del mando del país por parte de los perpetradores. En síntesis, un golpe significaría el intento de remover ${ }^{10}$ al máximo ejecutivo del Estado por perpetradores provenientes de dentro del aparato estatal bajo el supuesto de que el proceso mismo debe ser ilegal, abierto, no meramente supuesto, y sin que haya necesariamente derramamiento de sangre. Si se quisiera entrever aquí el OLP, la única vía imaginable sería suponerlo implícito en la variable de ilegalidad del acto de remoción. Pero ello es insuficiente sea porque dicha ilegalidad es solo indicación parcial de una avería del OLP o sea porque ella no arrastra de por sí un golpe. El asesinato de un presidente, por ejemplo, que se traduce en una interrupción anómala de un mandato, es ilícita, pero está lejos de sustentar un golpe. El valor inherente de la variable del OLP también se manifiesta cuando se considera que este puede ser quebrado sin que necesariamente medie una interrupción ilegal de un mandato ${ }^{11}$. Ahora bien, la variable de la ilegalidad del acto de remoción en la definición de golpe ha sido precisada con el tiempo. Como efecto de esta precisión ${ }^{12}$ fue posible distinguir el golpe de reemplazos no programados de un mandatario que, sin embargo, podían ser legales, como sucede con el impeachment (Marsteintredet y Malamud, 2019: 2). Ello aclaró que cuando se habla de una remoción irregular o anómala aún no se está diciendo que sea ilegal. Así como en su momento se esclareció el papel de la ilegalidad en la definición del golpe, urge ahora dar un paso adicional, elevando la variable OLP como parámetro central de la definición de golpe de Estado.

\section{HACIA UNA EXTENSIÓN DE LOS ATRIBUTOS QUE DEFINEN GOLPE DE ESTADO}

Si bien es cierto que la estructura trifásica (perpetrador/objetivo/táctica) de la definición de golpe es hoy preponderante, es justo reconocer que no faltaron

10 Para Powell y Thyne (2011: 252), la asunción real del poder por parte de los perpetradores del golpe juega un rol cuando este es exitoso, aunque conceden que estos pueden tener un interés en el cambio de las personas en el mando del Estado, pero no necesariamente buscar ser ellos mismos los que lo asuman.

11 Donde se aplicaría la teoría del «golpe jurídico de Estado» formulada por Stone-Sweet (2007: 916).

12 El tema de la ilegalidad aquí referido lo analizan Powell y Thyne (2011) bajo el atributo de «táctica». 
señales por tomar en serio algún tipo de dimensión macroinstitucional. Muchas veces estas señales permanecen empero encapsuladas. Así, la definición básica de golpe ofrecida por Marinov y Goemans (2014: 801) parte del patrón trifásico, aunque haga ajustes al dejar caer la idea del golpe como «intento», hable de uso o amenaza de la fuerza en vez de lo ilegal y se focalice en la toma del poder más que en la remoción de una autoridad. Sin embargo, páginas después, estos mismos autores completan esos parámetros con la idea de que golpe implica la "violación de acuerdos constitucionales o convencionales» adoptados en torno a cómo regular el cambio en los puestos directivos del Estado (ibid.: 808). Como estos autores distinguen del uso o amenaza de la fuerza el quebrantamiento de tales acuerdos, su complementación es un ejemplo de que un OLP como parámetro no estuvo del todo ausente del debate (Bartelson, 1997: 324; Stone-Sweet, 2007: 917). Sin embargo, no queda claro si las «provisiones constitucionales [...] de cómo se supone que el poder cambia de manos» (Marinov y Goemans, 2014: 808) suponen el régimen político en general o solo se refieren al acto específico de remoción. Lo propio, cuando algunos autores han preguntado con razón si a la luz de lo sucedido desde 2009 con las remociones de mandatarios en Honduras, Paraguay y Brasil, tiene aún sentido hablar de golpe «en ausencia de una ruptura institucional» (Pitts et al., 2016: 334, mis itálicas), no ha quedado claro qué significa «institucional». La confusión crece cuando se afirma que un golpe afecta el "Estado de derecho» (Martínez, 2014: 209; Pitts et al., 2016: 344), las "políticas» (Aksoy et al., 2015: 209), el «régimen» (ibid.: 428) o incluso el "Estado» (Marsteintredet y Malamud, 2019: 10). En caso de que los autores llegaran a la idea de que lo que se afecta es el régimen, es posible que bajo este no se entienda un conjunto de reglas, sino «el reemplazo de un grupo de elite» (Aksoy et al., 2015: 423). Pero incluso si se superara este escollo y se conectara régimen a un conjunto de reglas, el nuevo dilema es que no queda claro qué tipo de reglas se avizoran. Así, Marsteintredet y Malamud (2019: 2) escriben que el acto ilegal que caracteriza al golpe «también envuelve normalmente la suspensión del orden constitucional». Pero cabe cuestionarse: ¿solo «normalmente»? ¿Implica aquí suspender el orden constitucional desmontarlo en su integridad? ¿Abarca ello también cambios entre subtipos de regímenes o solo aquellos que se dan cuando un régimen pasa a ser otro? Y en caso de que esto se aclarara, ¿no correspondería entonces ampliar con esta variable al vigente canon trifásico de definición de golpe? Mientras Marsteintredet y Malamud (2019: 10) iluminan las dificultades para dirimir cuándo una remoción irregular es ilegal o legal, no contamos con esfuerzo comparable en la academia dedicada al golpe para distinguir entre ilegalidad e inconstitucionalidad, o entre orden constitucional y OLP. 


\section{DISTINGUIR REVUELTAS DE PALACIO Y PRECISAR LA COMPOSICIÓN DEL ORDEN LEGAL PARCIAL}

La incorporación del OLP genera de entrada dos efectos analíticos. El primero tiene que ver con criticar a quienes (Huntington, 1968: 201; Martínez, 2014; Derpanopoulos et al., 2016: 1) llaman golpe lo que en realidad son interrupciones irregulares de mandato de un presidente en el sentido de un recambio de persona -0 , si se prefiere, de este y las elites (González, 2001: 92) que lo acompañan — sin impacto sobre el OLP propiamente dicho. En lugar de ello conviene distinguir entre la víctima de un golpe (el Gobierno o el mandatario) del blanco del mismo (el OLP). Cuando la «salida irregular» (Marinov y Goemans, 2014: 423) alcanza su víctima, pero no toca el blanco, entendido como el «conjunto de reglas que regulan cómo el Estado es gobernado» (Marsteintredet y Malamud, 2019: 10), en vez de golpe será mejor hablar de una "revolución de palacio» (Luttwak, 1969: 18). No se produce aquí un cambio en las «reglas de cómo gobernar», mucho menos de las que sostienen todo un régimen (Geddes et al., 2014: 314,316). Esta precisión impide que se confunda una "revolución de palacio» con otros tipos de interrupción irregular de mandato que van más allá de mero recambio de personas (Geddes et al., 2014: 316). Es justamente la confusión entre víctima y blanco de un golpe lo que lleva a Marsteintredet y Malamud (2019: 10) a concluir que «reduciendo la víctima del golpe al Gobierno, un golpe no necesita por definición un cambio en la naturaleza del régimen», aunque reconocen que el golpe tendrá "consecuencias" sobre aquel. Al contrario, el golpe debe producir tanto una víctima (el gobernante) como afectar un blanco (el OLP). Con ese paso se eleva al OLP a ser un "elemento constitutivo» de la definición de golpe. Cuando Marsteintredet y Malamud ven al OLP como aquello sobre lo cual el golpe tendrá consecuencias en vez de concebirlo como variable constitutiva de su definición, confirman que subestiman el rol del OLP en la definición de golpe por mucho que hablen de que golpes «normalmente envuelven la suspensión del orden constitucional».

El segundo efecto es la explicitación de la naturaleza dual del OLP. Este puede presentarse en dos modalidades que, parafraseando a Kotowski (2009:215), son la reducida o la amplia. Es reducida cuando el OLP se refiere a las normas que regulan lo que es un subrégimen político del Estado, mientras que es amplia cuando concierne a aquellas que atañen al régimen propiamente tal. Una cosa es moverse de un régimen democrático a uno autocrático (versión amplia), y una distinta moverse dentro de una dictadura monárquica a una militar (Geddes et al., 2014: 316). La variable OLP en la definición de golpe se aplicará tanto cuando el quiebre del OLP afecte las reglas del subrégimen, como cuando afecte a las más agregadas del régimen. 
Es reciente la visibilización radical del OLP en la definición del golpe, lo que torna inteligible la pregunta de qué sucede si la remoción irregular de un mandatario no es concomitante con la ruptura del OLP — efecto inherente a todo golpe de Estado—, sino con su rescate. Queda, pues, esbozar un concepto más apropiado que el del golpe de Estado para tal situación.

\section{DEL GOLPE DE ESTADO AL REENCAUZAMIENTO DE ESTADO}

\section{NATURALEZA DEL REENCAUZAMIENTO DE ESTADO Y SUS PARÁMETROS DE PLAUSIBILIDAD}

Golpe y reencauzamiento de Estado comparten características. Su definición se hará evitando un diagnóstico artificialmente reconstruido ex post facto (Powell y Thyne, 2011: 252). Ambos son procesos rápidos y conllevan una remoción irregular de un mandatario. Sin embargo, solo el golpe supone un quiebre generalizado del OLP, mientras que el reencauzamiento de Estado se usará cuando el OLP esté de antemano quebrado y la remoción pueda disparar una reparación potencial del mismo. Existen tres insumos para estimar la plausibilidad de que lo observado es un reencauzamiento de Estado y no un golpe. Primero debe analizarse cómo gobernó el presidente depuesto en términos de su proclividad de haberlo hecho conforme a derecho. Si antes de su remoción irregular el depuesto gobernó violando sistemáticamente el OLP, entonces crece la chance de que su mera remoción venga conectada al arranque potencial de una reparación del orden. No por casualidad algunos académicos hablan de beneficios democratizantes por el solo hecho de que un gobernante avieso haya sido depuesto (ibid.: 258) ${ }^{13}$. En segundo lugar, deben sopesarse los contenidos de las primeras medidas legislativas del nuevo Gobierno. Si éstas contienen explícitamente medidas dirigidas a reparar el OLP y no están diseñadas solo para restaurar la capacidad coercitiva bruta del aparato estatal, sube la plausibilidad de que se pudo haber producido un reencauzamiento de Estado. Esta plausibilidad se maximiza, en tercer lugar, si el llenado del vacío jurídico generado por la remoción irregular de un mandatario se sujeta ostensiblemente a lo que el OLP quebrantado aún irradia como mandato procedimental. El reencauzamiento de Estado es una técnica de cortísimo plazo cuya naturaleza no puede ser deducida de la consumación de específicas aspiraciones de política pública. En contraposición a una revolución es, como se ha sostenido del golpe (Luttwak, 1969: 12), una

13 Powell y Thyne lo ejemplifican con el caso de Mugabe en Zimbabue. 
técnica neutral. Tampoco juegan un rol en su definición las justificaciones que los protagonistas proclamaran. Las capacidades restaurativas de un reencauzamiento de Estado deben ser tomadas solo como potenciales. Es por ello que la definición de reencauzamiento de Estado tampoco depende del éxito restaurador que se pueda finalmente alcanzar. En términos dialécticos el reencauzamiento de Estado es una suerte de negación de una negación, o sea, significa un movimiento contra algo previamente contrariado. Por cierto, la intuición detrás del concepto de reencauzamiento de Estado está sembrada en una obra de Naudé escrita en 1639 (1989: 114), que pensó que entre las motivaciones que pueden hacer del golpe de Estado algo plausible, esta aquello que llamó «rétablissement, et restauration des États». Este es un antecedente de la idea reencauzamiento de Estado, salvando la diferencia de que el reencauzamiento, más que referirse al Estado como un todo, se centra solo en uno de sus órdenes parciales legales. Además, para Naudé (1989: 101) los golpes son procesos ilegales por definición, mientras que reencauzamiento de Estado no cumple con ese requisito.

\section{VÍAS ALTERNATIVAS A LA IDEA DEL REENCAUZAMIENTO DE ESTADO}

Una vía de reforzar la pertinencia conceptual del reencauzamiento de Estado pasa por escudrińar si lo que se presume lograr con este concepto no ha sido resuelto por los análisis que diferencian golpe de otros fenómenos semejantes como revolución, o por aquellos abocados a distinguir subtipos de golpe. Sin pretender agotar aquí las salidas derivables de ambas fuentes, se pueden delinear algunas dificultades inherentes a ellas. En cuanto a la primera estrategia, se ha sugerido, por ejemplo, que a diferencia de las revoluciones, los golpes contendrían una predisposición hacia la estabilización de los procesos estatales antes que a generar su conmoción (Moore, 2010: 126). Lo que el reencauzamiento pretende ya lo parece ofrecer el golpe de por sí. En esa línea se ha sugerido que los que conceptualizan el golpe con un foco puesto en una desestabilización del orden legal no atenderían la dimensión política inherente a estos procesos, desmereciendo así el efecto de continuidad institucional obtenible desde un golpe de Estado (Sampford, 1989: 257). El problema de esta estrategia es que la búsqueda de una restauración del orden lo más pronto posible no anula el hecho de que el golpe haya de todos modos quebrantado el OLP. El que un golpe en su definición no dependa de un programa de transformación socioeconómica epocal de un país, no altera el hecho de que quebrar algo menos ampuloso como es el OLP conlleva sus propios grados de conmoción. Amén de que lo que los perpetradores pueden buscar estabilizar, es más la capacidad de coerción pura del aparato estatal que el OLP afectado. La segunda estrategia es la de la elaboración de subtipos 
de golpe. Siendo satisfactorio remitirse a la crítica sistemática que de ella han hecho Marsteintredet y Malamud (2019), es suficiente aquí ilustrar esta estrategia seleccionando tres subtipos de golpe que parecerían atender el reclamo por incorporar la idea de reparación de un OLP. Por un lado está el denominado "guardian coup" (Moore, 2010: 126), caracterizado por su intención de recuperar una "gobernanza efectiva». El problema aquí es que este subtipo supone elementos ajenos al reencauzamiento, como es basarse en militares preclaros, buscar revertir un colapso operacional de la seguridad pública y no de la reglas de acceso al poder, reducirse eventualmente a la recuperación de capacidad coercitiva bruta del aparato estatal e implicar una misión moral de purificación del orden existente (Huntington, 1968: 225, 226). Otro ejemplo viene de la investigación sobre el vínculo entre golpes y democratización (Derpanopoulus et al., 2016) o sobre el "golpe democrático» (Varol, 2012). Si bien estadísticamente los golpes han llevado más frecuentemente hacia la autocracia que hacia la democracia (Derpanopoulus et al., 2016: 2), el solo hecho de considerar que hay golpes que pueden llevar a la democracia deja aparecer un tono positivo en ciertos tipos de golpes, así como lo hace la idea de un reencauzamiento. Pero ello no anula el que el golpe benigno absorba su positividad de romper un orden que está funcionando y que no deja de ser orden por no ser democrático. Un tercer caso de subtipo es el llamado autogolpe. Se propuso para el caso boliviano aquí analizado al aducirse que hubo golpe, pero que quien lo perpetró fue el propio Evo Morales por sus ataques sostenidos a las reglas democráticas ${ }^{14}$. Esta alternativa tiene un atractivo coloquial, pero no es técnicamente firme. En relación con la idea del autogolpe Marsteintredet y Malamud (2019: 13) sugieren pertinentemente usar más bien el concepto de «incumbent takeover». Sin embargo, ni el concepto de incumbent takeover introducido por Svolik (2015: 730), ni el de una "terminación endógena», como sugiere Maeda (2010: 1130), pueden reemplazar el concepto de reencauzamiento de Estado, pues en ambos no hay remoción alguna del mandatario - como no la hay en el autogolpe-, cosa que el reencauzamiento sí implica, como lo hace el golpe (Marinov y Goemans, 2013: 808). Además, incumbent takeover y terminación endógena pueden implicar quebrar un orden, cosa lógica para un golpe, pero no para un reencauzamiento. En resumen, sin descartar que conceptos convencionales hagan superflua la idea de reencauzamiento de Estado, resulta que las alternativas presentan suficientes obstáculos analíticos.

14 Fue la conclusión a la que llegó el secretario general de la OEA. Disponible en: https:// bit.ly/3u8W3wf. 


\section{EL REENCAUZAMIENTO DE ESTADO SI SE SUSTITUYÓ EL ORDEN QUEBRADO}

Un escollo del concepto del reencauzamiento de Estado sería contraargumentar que si su premisa es la presencia de un OLP previamente quebrado, ¿qué pasa si el orden quebrado ya cedió su lugar a uno nuevo? Imagine uno que el daño propiciado al orden democrático de un país fue tal que se acabó erigiendo una autocracia. En tal caso, sí habría habido un orden (autocrático) que quebrar, con lo cual el golpe - y no el reencauzamiento de Estado — sería lo que cabe diagnosticar. Esto parece caracterizar la renuncia de Evo Morales pues, como se verá en seguida, el daño que infringió al orden democrático fue tal que su renuncia pudo haber sido concomitante con un quiebre del orden autocrático que él mismo ayudara a instaurar. Así, los movilizados no habrían buscado reparar lo quebrado; habrían llanamente quebrado un orden que ya había sustituido a otro orden que, a más de quebrado, había desaparecido. Obviamente, lo desaparecido no se puede reencauzar, sino eventualmente resucitar. Para desvirtuar esta crítica se puede tomar el caso boliviano como ilustración. Sigamos por un momento a quienes han mantenido que, pese al daño proferido a la democracia durante la regencia de Evo Morales, Bolivia aún era democracia. De hecho, Levitsky y Way (2015: 47) consideraron a Bolivia un caso de «borderline regime» aún anclado en la democracia. Aquí el concepto de reencauzamiento de Estado confronta un problema, pues un orden severamente dañado no es sinónimo de uno quebrado. Y si no hay un OLP quebrado, no aplicaría la técnica del reencauzamiento. Bien vistas las cosas, este escenario hipotético permite ahora delinear el alcance pleno del concepto de reencauzamiento de Estado. Resulta que este no solo sirve para la situación de una remoción irregular concomitante a un orden ya quebrado de antemano, sino a uno casi quebrado (borderline regime), con la diferencia de que aquí el reencauzamiento de Estado no repara, sino que reanima un orden moribundo. La remoción irregular de Evo Morales conllevaría hipotéticamente la potencialidad de revertir la cualidad fronteriza del régimen, adentrándolo más hacia el dominio democrático del que había sido crecientemente alejado. La cuestión se complica si se demostrara que el OLP alguna vez fue quebrado, mas acabó reemplazado por otro antes que se produzca la remoción del mandatario. Tanto la idea de un orden quebrado como la de uno borderline pierden aquí sentido. Curiosamente, Levitsky y Loxton (2013), años previos a su teoría de Bolivia como «democracia al borde», afirmaron que Bolivia era ya un caso de régimen no democrático del tipo autoritarismo competitivo ${ }^{15}$ (Landau, 2013: 13). De ser

15 Barrios-Suvelza (2017) cree que el país dejó el ámbito de la democracia recien el 2013, pero duda que el subtipo autoritario sea el del autoritarismo competitivo. 
así, no habría nada para reparar, por lo que habiendo un nuevo orden imperante la opción del golpe aparecería como mejor concepto descriptor. Si se agudiza la reflexión existe, sin embargo, un aspecto central a considerar antes de descartar el reencauzamiento de Estado para este escenario. Incluso si se asumiera que los daños infringidos por Evo Morales fueron tales al punto de dar lugar a una autocracia, ello no necesariamente conlleva que se haya producido un reemplazo pleno, sistemático y simbólico de un régimen por otro. Aquí el positivismo de Kelsen (1949: 118) no ayuda, pues no prevé que el quebrantamiento no legal del orden pueda arrastrar cierta legalidad previa y por ello, a pesar de estar quebrado, aún incidir sobre la conducta social; tampoco distingue entre quiebre exitoso de un orden y éxito en la reposición del orden previo, pues derrumbe y reemplazo están en Kelsen amalgamados (ibid.: 117). Sucede, empero, que el orden a considerar como referente del análisis puede que sea, paradójicamente, el que ha sido quebrado (lo que mantendría al reencauzamiento como opción), si es que el régimen que se supone lo debe sustituir no lo logra por no ser aún operacional y estructuralmente maduro. Este escenario de tomar un régimen quebrado como referente parece desquiciante, pero no es nuevo en la teoría del régimen de Estado. Przeworski (2013: 546), por ejemplo, llamó la atención sobre escenarios en los que un país no tiene régimen e impera el "tumulto», aunque ello no se equipare a lo que Snyder (2006: 224) llamó un «no estado». Si bien la situación en Bolivia fue menos caótica que un escenario de tumulto à la Przeworski, lo cierto es que la idea de tumulto en un Estado sin régimen devela escenarios de compleja articulación regimental. El régimen autocrático que en Bolivia pudo haber tomado cuerpo como efecto de las violaciones previas pudo haber sido aun incapaz de imponerse, generando una concurrencia interna entre regímenes. Otro enfoque que se entretuvo con escenarios paradójicos fue el propuesto por O’Donnell cuando advertía que una cosa era tener un "gobierno» democrático luego de la primera elección en transición del autoritarismo a la democracia, y otra tener un «régimen democrático» (O’Donnell, 1994: 56). Más tarde añadió que una cosa era tener un «régimen» democrático, y otra distinta, alcanzar un «Estado» democrático (O’Donnell, 2008: 31). O tómese la imagen basada en los trabajos de Linz que Armony y Schamis (2005: 125) usan para dar cuenta de escenarios de fluidez institucional entre democracia y autocracia, que justificarían hablar en tal caso de una «situación» más que de un régimen estatal. Finalmente, considérese todo el complejo de teorías sobre regímenes híbridos. Lehoucq (2020: 132, mis itálicas) en su reciente análisis sobre el caso boliviano, sostiene que la remoción de Evo Morales devela que este buscaba «transformar un régimen híbrido en una autocracia electoral plena». En resumen, cuando un nuevo OLP está en camino, pero no es capaz de desplazar al anterior OLP quebrado, entonces 
reencauzamiento de Estado sigue siendo una técnica plausible. Una interrupción irregular de mandato presidencial sería concomitante a un OLP quebrado que, sin embargo, puede seguir fungiendo como el referente aún válido en lo simbólico, funcional y en lo que se percibe como legítimo. El orden sustituyente estaría en tensión con lo que la Constitución aun pretende, y mientras ese nuevo orden no sea eficaz porque los «individuos [... ] no se comportan grosso modo en conformidad con el nuevo orden", este no es el orden válido (Kelsen, 1949: 118). Cuando un golpe quiebra un OLP, si bien defenestra mecanismos concretos que han estado regulando operativamente el acceso al poder, puede que tarde más en subvertir irreversiblemente la subjetividad prevaleciente en la sociedad sobre lo que se supone es un orden no solo legal, sino correcto.

Todo esto lo ilustra el caso boliviano. El día que Evo Morales renuncia, los actores políticos partían de que el orden prevaleciente era el democrático, no importando el grado de daño que se la había proferido. Los ciudadanos participaron disciplinadamente en las elecciones del 20 de octubre de 2019, a pesar de las denuncias de permanente ventaja desproporcional del oficialismo en la campaña ${ }^{16}$. Dada la inmadurez ontológico-operativa del nuevo régimen autocrático en ciernes, su tensión con el marco constitucional formalmente vigente y la fuerza simbólica del OLP quebrado, en Bolivia el orden nuevo fue incapaz de primar, haciendo que el OLP quebrado aún apareciera como algo susceptible de reparación.

\section{EL REENCAUZAMIENTO DE ESTADO CUANDO SON ÓRGANOS LEGALES LOS QUE PARTICIPAN DEL QUIEBRE}

Otro contraargumento es preguntarse cómo pudo darse una ruptura del OLP en Bolivia habida cuenta de que su supuesta destrucción fue consistentemente avalada por un Tribunal Constitucional ${ }^{17}$. Uno podrá tener reparos morales, políticos o técnicos frente a los jueces, pero una vez que deciden reproducen legalidad (Stone-Sweet, 2007: 916), más allá de su forma de designación, del grado o no de venalidad, o de la incoherencia técnica de su ratio decidenci. De entre los varios enfoques que relativizan este crítica, hay dos combinaciones que se pueden mencionar aquí ${ }^{18}$. Primero está la combinación del «constitucionalismo abusivo» (Landau, 2013:4) con «legalismo autocrático» (Scheppele,

16 Sobre esas fallas de la competencia ver Informe de Unión Europea (2019).

17 Agradezco a uno de los árbitros anónimos por desplegar este contraargumento.

18 Otros enfoques útiles serían el de la prevaricación del juez (Fischer, 2018) y el del derecho a la resistencia de los ciudadanos cuando «alguien» (como un Tribunal Constitucional) decide eliminar el «orden» constitucional (Isensee, 2013). 
2013: 548). Aquel, aunque focalizado al tema del remplazo/enmienda constitucional para averiar la democracia, alerta que será justamente jugando con las reglas constitucionales como se puede producir un desmonte de las instituciones por parte de los regentes. Para el «legalismo autocrático», entendido como uso y creación de legalidad (lo cual abarca el control de constitucionalidad) por parte de representantes democráticamente electos que buscan consolidarse autocráticamente en el poder, es normal que se usen "formas constitucionales» para realizar fines iliberales (Scheppele, 2018: 562). Se deduce que es posible que un tribunal constitucional, en lo material, decida de tal modo que sustente el desmantelamiento de un orden legal como no lo hizo la Corte Constitucional colombiana en su decisión contra la tercera reelección de Uribe (Landau, 2013: 40) y sí lo hizo el Tribunal Constitucional boliviano en relación con Evo Morales. Es pues posible que se produzca un desmantelamiento del orden siguiendo vías legales y constitucionales (ibid.: 57; Scheppele, 2018: 545), con un Tribunal Constitucional como actor ${ }^{19}$. La segunda combinación conecta Kelsen con Radbruch, pues puede uno preguntarse cuánta legalidad acompañaba la acción del Tribunal Constitucional boliviano. No se trata de demostrar que técnicamente la conclusión de ese tribunal sea rebatible $e^{20}$ en términos de contenido (Kelsen, 1949: 113). El tema es que así como uno da por válida una norma por producirse según un procedimiento preestablecido (ibid.: 115) - y si no es así, ella no pertenece al orden legal (ibid.: 122) - , así depende la pertenencia de la decisión del juez al orden legal de si se cumplen exigencias formales, como la de que el juez sea independiente ${ }^{21}$. Afirmar que la decisión de una jueza coerza, no resuelve el dilema de si pertenece al orden legal en términos de validez (ibid.: 122, 123). Puede dudarse de la legalidad del Tribunal Constitucional boliviano desde que asumió un "papel constituyente que no le corresponde» (Viciano y Moreno, 2018: 171) o porque admitió una demanda de constitucionalidad de los preceptos constitucionales mismos, algo no previsto por la Constitución

19 Eso precisamente inspira la idea del «golpe de Estado jurídico» (Stone-Sweet, 2007).

20 Tanto desde la politología como desde la jurisprudencia se ha criticado el ratio decidenci que elaboró el Tribunal Constitucional de Bolivia sobre el supuesto derecho humano de Evo Morales a la reelección. Allá se habla de una «razón absurda» (Levitsky y Murillo, 2019), acá se ha dicho que fue fruto de «confusión doctrinal y una errónea interpretación de categorías» (Viciano y Moreno, 2018: 166). En su balance doctrinal, la Comisión de Venecia (2018: 26) concluye que no hay derecho humano a la reelección.

21 Analistas cercanos al proceso de cambio social bajo Evo Morales reconocen la ausencia de una justicia independiente en el país (Farthing, 2020: 11). Sobre la crisis de independencia del control constitucional boliviano bajo Evo Morales, véase Castagnola, A. y Pérez-Liñán, A. (2011). 
boliviana (ibid.: 185). En realidad, el legalismo autocrático no sigue un libreto positivista como supone Scheppele (2018: 563), pues se olvida de que si bien el positivismo aboga por entrever lo legal sin depender de contenidos, lo legal no puede ser arbitrario en lo formal. Sus altas exigencias de rigor formal son $s u$ contenido, y si eso ha sido violado, la legalidad del Tribunal Constitucional queda reducida a una no legalidad de apariencia legal. El Tribunal Constitucional boliviano, usando el vocabulario del legalismo autocrático, era una cascara vaciada de su «núcleo moral» (ibid.: 583). Al violarse competencias, es plausible que las decisiones del Tribunal Constitucional — parafraseando a Radbruch (2003) — generaran «derecho incorrecto», o incluso un no derecho legal, o peor, no produjeran derecho del todo. Si la compatibilidad de un Tribunal Constitucional con el desmantelamiento del orden es plausible desde la primera combinación analítica, mucho más lo es a la luz de la segunda.

\section{EL REENCAUZAMIENTO DE ESTADO CUANDO PESA LA INERCIA CONCEPTUAL O SE ADUCE POLITIZACIÓN DEL CONCEPTO. INDIFERENCIA FRENTE A AUTODESCRIPCIONES Y PROBLEMAS DE APLICABILIDAD A LO AUTOCRÁTICO}

Wolff (2020: 176) ha criticado la teoría aquí propuesta argumentado que el golpe no requiere romper un orden constitucional y que, no por nada, las definiciones corrientes evitan incluir lo que se ha llamado aquí el OLP. Ciertamente, si uno se aferra a la visión trifásica, lo de Bolivia podría ser golpe incluso si no se quebrara el OLP. Pero se trata precisamente de entender este estiramiento del concepto de golpe como obstáculo cognitivo, venciéndolo al añadir el OLP como cuarto elemento de su definición. Y recién eso posibilita abrir la mente a un escenario en el que no se puede ya quebrar un OLP por venir quebrado de antemano ${ }^{22}$. La segunda crítica de Wolff es que reencauzamiento acabaría siendo un concepto político que lo hace inservible, pues antes de decidir si hubo golpe, habría que dar una respuesta definitiva sobre si hubo o no violación del orden constitucional en el pasado reciente. Esta crítica no convence, pues así como para hablar de golpe se deben confirmar las datos respaldando la tríada perpetrador/objetivo/táctica, no se entiende por qué diagnosticar la salud del OLP en el momento de darse la remoción anormal sería algo político. El diagnóstico de la cuarta variable puede ser objetivo,

22 Wolff (2020: 176) tiene razón en advertir que hablar de ruptura del «orden constitucional» parece implicar al todo constitucional y no (solo) a un OLP. El texto en cual se basa Wolff para su critica contenía esa vaguedad que ahora se aclara con la teoría del OLP. 
aunque realizar dicho diagnóstico previo a los acontecimientos no sea sencillo (Landau, 2013: 48), pero tampoco lo es establecer definitivamente los datos que respalden los otros atributos. Wolff (2020: 177) complementa su crítica sosteniendo que mientras les sea posible a los potenciales perpetradores de un golpe señalar una plausible violación previa de un orden constitucional, ellos podrían rechazar que se les acuse de golpistas. Aquí Wolff da por hecho que se trata de golpistas (aunque potenciales), mientras que en el análisis aquí propuesto no se asume que lo sean hasta que no se escudriñen los atributos, incluyendo el OLP. Además, la utilidad del concepto de reencauzamiento de Estado va por separado de la indisposición moral que los actores políticos involucrados pudieran tener en relación con el adjetivo con el que quisieran entrar en la historia. Son dos dimensiones que no deben confundirse: la objetiva de diagnóstico de un proceso político y la de la esfera de simbologías que cultivan los actores. En su última crítica Wolff (2020: 177) deja escapar el quid detrás de la idea de reencauzamiento. Si se produce un golpe contra un orden inconstitucional, él dice que la mayoría de académicos hablarán de golpe, pero Wolff no resuelve con eso el caso en el que ese orden inconstitucional hubiera estado ya quebrado. La teoría del reencauzamiento de Estado supone que se haya quebrado un OLP, no un OLP que haya sido necesariamente constitucional. Por otro lado, si había un orden que quebrar, golpe es el mecanismo más probable sin ser relevante que haya sido un orden inconstitucional. En efecto, si se afirma que la mayoría de los golpes suceden dentro de autocracias (Thyne y Powell, 2016: 193), ¿en qué medida son aplicables los conceptos de golpe y reencauzamiento cuando el régimen es autocrático? Si la definición de golpe debe conllevar el quiebre de un OLP que incluye disposiciones constitucionales, ¿hay golpe cuando se produce dentro de la autocracia, más aún si el resultado es quedarse en ella? Algunos académicos hablan de regulaciones de tipo constitucional, incluso en regímenes autocráticos (Svolik, 2012: 4). No es este el lugar para discutir si tales regulaciones en una autocracia merecen el calificativo de constitucionales. El punto por el momento es que en las autocracias existe una institucionalidad (Gandhi, 2008) peculiar que regula el acceso al poder estatal. Determinados subtipos autocráticos como la monarquía o aquellos que incorporan procesos electorales (Gandhi, 2008) develan reglas relativamente genéricas y claras, mientras que otros, como los de tipo personalista (Geddes et al., 2014), son más nebulosos al respecto. Así como sucede en un régimen democrático, dentro de la autocracia un golpe podrá encontrar lo que tiene que quebrar. Si la interrupción irregular del gobierno de un autócrata conlleva el quiebre de las reglas de cambio en el poder autocráticamente diseñadas, entonces se habrá producido un golpe (Svolik, 2012: 4), supuesto que se cumplen sus demás requisitos. Si tal interrupción acontece cuando estas reglas estaban de antemano quebradas, 
entonces se sospechará de un reencauzamiento de Estado dentro del ámbito autocrático. Por supuesto, si la interrupción de un mandato conlleva un OLP previamente quebrado, el reencauzamiento de Estado no es necesariamente el único desenlace imaginable. Es teóricamente posible que los perpetradores no tengan la intención de iniciar la reparación del orden quebrado.

\section{LA APLICACIÓN DEL NUEVO CONCEPTO AL CASO CONCRETO}

\section{BOLIVIA COMO REFERENTE DEL REENCAUZAMIENTO DE ESTADO}

El desmontaje sistemático del OLP en Bolivia es la razón para afirmar que lo que se produjo fue un reencauzamiento de Estado y no un golpe. El OLP comenzó a ser quebrado a más tardar desde el 2013. Ese año los jueces del Tribunal Constitucional ${ }^{23}$ desconocieron una disposición transitoria constitucional que limitada la reelección de Evo Morales, a la vez de que le quitaron efecto al artículo constitucional que no permite más de dos mandatos consecutivos. Los jueces argumentaron que el primer mandato de Evo Morales no contaba, ya que se había producido en una república que ya no existía luego de que en 2009 había sido sustituida por el «Estado plurinacional». Y eso a pesar que Evo Morales, a fin de desbloquear el voto aprobatorio de la nueva Constitución, había anunciado públicamente que, en aras del país, había aceptado el límite a la reelección ${ }^{24}$. Pero la más gruesa violación ocurriría en 2016, cuando Evo Morales desconoció los resultados del referéndum inducido por él mismo para que el pueblo aprobara o rechazara una reforma de la Constitución que permitiera la reelección indefinida ${ }^{25}$. Evo Morales perdió el referéndum y la Corte Electoral eludió aplicar la ley electoral ${ }^{26}$ que le conminaba a imponer los resultados de cualquier referéndum. En lugar de acatar la ley y aceptar el veredicto democrático, Evo Morales buscó sin demora vías

23 Declaración del Tribunal Constitucional 003/2013. Si bien el Tribunal Constitucional jugó constantemente un rol facilitador, no fue el agente determinante, pues se limitaba a refrendar los pedidos de Evo Morales que calculaba cuando convenía convocarlo. Las decisiones de este tribunal se centraron en un OLP del Estado, no en la norma básica. Por estas razones - y ya que no dice nada sobre la remoción de un presidenteno aplica aquí la teoría del golpe jurídico del Estado de Stone-Sweet (2007: 916).

24 «Morales renuncia a segunda reelección para acuerdo en Bolivia». Reuters, 20-10-2008. Disponible en: https://reut.rs/3s5zxT7.

25 El rechazo a la reelección alcanzó el 51,34\% frente al 48,66 \% del apoyo. Disponible en: https://bit.ly/3pzwuRo.

26 Art. 15 de la ley electoral boliviana. 
para insistir en una candidatura ilegal. Para ello acudió de nuevo al Tribunal Constitucional para habilitar su reelección. Esta vez los jueces decidieron el 2017 declarar inaplicable el art. 168 de la Constitución, que establece el límite a la reelección ${ }^{27}$. Aplicando esta vez un control de convencionalidad, los jueces arguyeron que de acuerdo al art. 23 de la Convención Americana de Derechos Humanos, Evo Morales se beneficiaba del derecho a la reelección indefinida por tratarse de un derecho humano ${ }^{28}$. Como en 2013, esta decisión volvió a vulnerar al poder constituyente. Finalmente, en las elecciones de 2019, con Evo Morales como candidato de por sí ilegal, el pueblo como poder constituido puede haber sido nuevamente desconocido, pues queda la duda de si es fidedigno el resultado de las elecciones de octubre de 2019, donde 0,57 puntos porcentuales salvaron supuestamente a Evo Morales del balotaje. Agregando todo esto se puede concluir que el daño fue sistemático, ya que se violentó el 2016 y el 2019 la democracia (basada en el pueblo como cuerpo electoral regular decisorio no constituyente); y se afectó, además, el 2013 y 2017, lo que podría denominarse la demoarquía (concerniente al pueblo como origen de la constitución). Un OLP se quiebra cuando una acumulación de daños en variables sensibles (como la seguridad jurídica o la validez del orden legal) de las estipulaciones normativas dirigidas a regular el régimen político — tanto en la dimensión del poder constituido como del constituyente- impide que ellas regulen operacional y estructuralmente la conformación del máximo poder político del Estado, sin que ello implique necesariamente que el orden quebrado no afecte aún el comportamiento de la gente. A la luz de la envergadura del quebrantamiento del OLP, la decisión de Evo Morales de renunciar no solo supuso un recambio irregular de personal en la dirección del Estado boliviano, sino que abrigó simultáneamente la oportunidad de iniciar la reparación del OLP previamente quebrado. La instalación del nuevo Gobierno apareció como potencial reencarrilamiento del país en los rieles de la legalidad.

\section{PRUEBAS ADICIONALES DE QUE NO HUBO GOLPE}

La plausibilidad del reencauzamiento de Estado como mejor forma de describir lo sucedido no acaba ahí. En el caso boliviano, varios parámetros usualmente considerados para afirmar la existencia de un golpe no se dejan probar. Un factor que atrajo la atención fue el rol jugado por los militares

27 Decisión 0084/2017.

28 Esta tendencia ya se vio en Costa Rica (2003), Nicaragua (2009) y Honduras (2015). $\mathrm{Al}$ respecto, véase Viciano y Moreno (2018: 171). 
durante esos días de conmoción nacional. Muchos tomaron las declaraciones del general Kaliman sugiriendo a Evo Morales a que renuncie minutos antes de que este lo hiciera, como la piedra de toque. Levitsky (2019) fue uno de los que dedujo el golpe de esas declaraciones. Su confianza apodíctica sobre su diagnóstico es inversamente proporcional a su interés por los datos del contexto inmediato y más general que rodearon al acontecimiento. Levitsky no ve como relevante, por ejemplo, que antes de que el general Kaliman hiciera su sugerencia el domingo 10 de noviembre, la Central Obrera Boliviana (COB), que Evo Morales adujo como pilar de su legitimidad ${ }^{29}$, también le había conminado a dejar el cargo. Más aún: en la madrugada de ese domingo, Evo Morales se enteró de que la auditoría electoral de la OEA estaba a punto de publicarse (Morales, 2020: 40). Las conclusiones de tal reporte, que mencionaban dolo en las elecciones, hicieron que Evo Morales pidiera, sin éxito, que no se publicara (id.) al intuir que tal noticia achicaba su margen de maniobra. La firmeza con la que Levitsky defiende que el golpe se sustenta en que la sugerencia del militar (cerca de las 15:50) se produjo antes que la renuncia (alrededor de las 16:50 horas ${ }^{30}$ ), es ya a la luz de estos datos debatible, pero pierde definitivamente norte cuando tiempo después se supo que antes del pronunciamiento militar Evo Morales había encomendado a su portavoz a que organizara una reunión con la oposición (Peñaranda, 2019: 237). Allí su portavoz comunica que el presidente ha decidido renunciar, pero espera que la oposición apoye la sucesión constitucional en favor de una correligionaria que fungía como presidenta del Senado. Esto cuadra con las memorias de Evo Morales (2020: 48), donde se advierte cómo el entonces presidente madura la decisión de renunciar muchas horas antes y con clara independencia del pronunciamiento militar que él menciona como una anécdota. Sus memorias dan a entender que lo decide así incluso un día antes, el sábado 9 de noviembre (id.) $)^{31}$. No sorprende, pues, que en su carta de renuncia Evo Morales no mencione la declaración del general Kaliman como causa de su salida. Debería llamar la atención adicionalmente que ningún militar asumió cargo alguno luego de los eventos y que a horas del juramento de la nueva presidenta, y siguiendo los protocolos preestablecidos, el comando general en pleno fue relevado. No se menciona que el lenguaje usado por el general

29 Según Morales (2020: 43), ese domingo por la mañana la misma COB que horas más tarde le pediría la renuncia, se había comprometido a recuperar el palacio al día siguiente en apoyo a Evo Morales.

30 Las estimaciones de las horas se extraen de Correo del Sur, 1-12-2019. Disponible en: https://cutt.ly/6ksKtCa.

31 A esa conclusión llega también Atahuichi (2020). 
Kaliman se hallaba explícitamente respaldado por la ley militar boliviana ${ }^{32}$. La razón que Evo Morales esgrime para la renuncia es que fue para evitar muertes entre los bolivianos ${ }^{33}$. Quien hubiera observado la evolución de la conducta de las FFAA bolivianas durante los 35 años después de la recuperación de la democracia, no se sorprendería del papel cauto y hasta indiferente que los militares jugaron durante esos días ${ }^{34}$. No deja de ser una ironía que cuando los militares bolivianos, al contrario de una historia proclive al alzamiento armado contra el Gobierno civil (Landau, 2013: 6), actúan de una forma relativamente institucional, sean tomados como los perpetradores de un supuesto golpe. Tal vez impresionados por un país aquejado en el pasado por prácticas militares desestabilizantes, los analistas prefirieron extrapolar el factor militar sin mayores consideraciones de contexto y asumieron que, ante una situación de crisis, los militares solo podían haber tenido un reflejo hacia la violencia, como si eso les fuera inextricable. El rompecabezas parecería cerrarse si se parte de que los militares suelen encarnar una fuerza conservadora cuya reacción ante un presidente como Evo Morales, considerado como progresista, solo puede haber sido la de su violenta expulsión en aras de la protección de los intereses amenazados por las transformaciones sociales en beneficio de los excluidos. Si bien tanto esta estrategia analítica simplista, cuanto la insistencia en la actuación del general Kaliman, aislada de todo contexto, son legítimas para concluir que hubo golpe, los datos expuestos revelan que una estrategia analítica más sensible al contexto y más exigente en lo conceptual, es más fructífera para ajustar mejor el diagnóstico a los hechos.

Hay algo más en favor de la teoría del reencauzamiento de Estado. Su plausibilidad recibe adicionales respaldos por el incumplimiento de condiciones adicionales que se suponen caracterizan un golpe. Como se dijo, Powell y Thyne (2011) postulan la ilegalidad como un rasgo de golpe y lo hacen con el fin de no confundirlo con relevos irregulares de presidentes que se hallan basados llanamente en el derecho de movilización de los ciudadanos. Para estos autores, movilizaciones de este tipo también pueden desembocar en una remoción irregular, pero no por ello son automáticamente ilegales. Los autores también insisten en que los perpetradores de un golpe deben provenir de dentro del aparato estatal. En el caso boliviano ni hubo necesariamente ilegalidad en el acto de remoción ni hubo actores urdiendo el desenlace desde

\footnotetext{
32 Art. 20.b de la Ley Orgánica de las Fuerza Armadas Bolivianas.

33 Véase nota 7.

34 El retirado general Kaliman enfrenta un litigio judicial acusado de no haber actuado proactivamente los días de crisis para resguardar la seguridad ciudadana. Disponible en: https://cutt.ly/nksK1YK.
} 
dentro del aparato estatal. Tampoco se cumple aquella condición (Varol, 2012: 297) en el sentido de que los militares deben ser proactivos, por lo que no será suficiente que las fuerzas del orden se nieguen a cumplir instructivos para reprimir. En Bolivia los militares fueron pasivos.

\section{LA PRUEBA FINAL}

La prueba final para el reencauzamiento de Estado es observar qué pasa con los tres parámetros de su plausibilidad sugeridos arriba. Primero, Evo Morales no solo fue el damnificado de una suspensión irregular de su mandato, sino que él mismo fue propulsor del quiebre del OLP. El solo hecho de su separación del cargo contenía la potencialidad de detener la erosión del OLP. En segundo lugar, la primera ley que sacó el nuevo Gobierno contiene propósitos de reencarrilamiento del país en la legalidad. En esta primera disposición ${ }^{35}$ se llega a excluir de las nuevas elecciones que se realicen a candidatos que hubieran ejercido el mando más de dos veces, revirtiendo ex post la negación de Evo Morales del resultado del referéndum de 2016. Luego de tres ańos de desconocimiento de la decisión soberana, la primera medida legislativa post-Morales repara dicha usurpación. En tercer lugar, las actuaciones dirigidas a cerrar el vacío de poder que siguen a la renuncia de Evo Morales se desplegaron en sujeción al marco constitucional ${ }^{36}$, lo cual fue refrendado por el Tribunal Constitucional, que avaló las modalidades de transición adoptadas ${ }^{37}$.

\section{CONCLUSIONES}

A fines de 2019 la política internacional fue sorprendida con la dimisión de Evo Morales de la presidencia de Bolivia luego de catorce años de gobierno. Los observadores se dividieron entre quienes vieron un golpe de Estado y quienes diagnosticaron lo contrario. Este artículo toma este evento como la ocasión para reflexionar sobre la potencia y los limites que tiene el concepto de golpe de Estado. Luego de un cotejo de conceptos y respaldos empíricos, el artículo concluye que el concepto de golpe de Estado no es apto para dar cuenta de este evento. Para llegar a esa conclusión, el artículo comienza con

Art. 19.II de la Ley 1266 de 24 de noviembre de 2019.

36 Según la cadena de sucesión prevista en art. 169.I de la Constitución boliviana.

37 "TCP avala sucesión constitucional en la Presidencia». El Deber, 12-11-2019.

Disponible en: https://bit.ly/3qwgYY1. 
un ajuste parcial del concepto de golpe de Estado, articulando diversas perspectivas, como las de la ciencia política, la teoría constitucional y la teoría del Estado. Sugiere ampliar la convencional estructura trifásica de atributos usados para definir golpe, con un cuarto atributo, el del orden legal parcial del Estado. Esta ampliación va acompañada de una teorización más detenida sobre la naturaleza del OLP y de cómo se engrana con el concepto más amplio de constitución. Este artículo encuentra que solo destacando el OLP se puede visualizar la posibilidad de un nuevo concepto que permita clasificar casos en los que la remoción anómala de un presidente no coincide con la ruptura del OLP por suceder cuando este ha sido quebrado de antemano. En tal caso, el artículo sugiere hablar de un reencauzamiento de Estado en vez de usar el concepto de golpe, estirándolo para dar cuenta de un hecho que carece de las premisas que un golpe de Estado exige. Luego de establecer los parámetros de plausibilidad de un reencauzamiento de Estado y de confrontar este esquema con diversas alternativas y contraargumentos que se le pudieran anteponer, el articulo sintetiza las virtudes del concepto a la luz de datos empíricos del caso boliviano. Este enfoque contiene una valía analítica más allá del caso boliviano, ya que puede repercutir en discusiones derivadas de reconocer que tanto golpe como reencauzamiento de Estado suponen la remoción de un presidente sin que se aplique el mecanismo de un acto electoral limpio. En consecuencia, ambas técnicas ponen sobre la mesa la cuestión de si son únicamente fórmulas de solución estrictamente extraídas del catálogo de procedimientos democráticos las que se deben emplear para neutralizar gobernantes democráticamente electos que, al día siguiente de su legal y legítima entronización, comienzan a desmantelar, a veces usando medios legales o constitucionales, el sistema que los llevó al poder.

\section{Bibliografía}

Aksoy, D., Carter, D. y Wright J. (2015). Terrorism and the fate of dictators. World Politics, 67, 423-468. Disponible en: https://doi.org/10.1017/S0043887115000118.

Armony, A. y Schamis, H. (2005). Babel in democratization studies. Journal of Democracy, 16, 113-128. Disponible en: https://doi.org/10.1353/jod.2005.0055.

Atahuichi, R. (2020). Evo Morales: «Pensé en tirarme monte adentro, selva adentro, para gobernar». La Razón, 30-08-2020. Disponible en: https://bit.ly/3itkDT7.

Barrios-Suvelza, F. (2017). ¿Qué tipo de régimen político impera en los países del nuevo constitucionalismo latinoamericano? Indicaciones desde el caso boliviano. Revista Latinoamericana de Política Comparada, 12, 71-101.

Barrios-Suvelza, F. (2018). El control contramayoritario como marco de análisis de la influencia del nuevo constitucionalismo latinoamericano sobre la democracia. Revista Española de Ciencia Politica, 47, 39-68. Disponible en: https://doi.org/10.21308/recp.47.02. 
Barrios-Suvelza, F. (2019). The Coup d'État that wasn't. Does the latest revolt in Bolivia Reveal limitations of a concept or the failure of scholars using it? I-CONnect [blog], 08-12-2019. Disponible en: https://bit.ly/2LOzqfd.

Bartelson, J. (1997). Making exceptions: some remarks on the concept of coup d'état and its history. Political Theory, 25, 323-346. Disponible en: https://doi.org/10.1177/0090591 797025003001.

Bermeo, N. (2016). On democratic backsliding. Journal of Democracy, 27, 5-19. Disponible en: https://doi.org/10.1353/jod.2016.0012.

Carrillo, L. (2019). La Revolución de las Pititas. En M. Vaca (ed.). La Revolución de las Pititas (pp. 43-50). La Paz: Página Siete.

Castagnola, A. y Pérez-Liñán, A. (2011). Bolivia. The rise (and fall) of judicial review. En G. Helmke y J. Ríos-Figueroa (eds.). Courts in Latin America (pp. 278-305). Cambridge: Cambridge University Press. Disponible en: https://doi.org/10.1017/ CBO9780511976520.011.

Collier, D. y Levitsky, S. (1997). Democracy with adjectives: Conceptual innovation in comparative research. World Politics, 49, 430-451. Disponible en: https://doi. org/10.1353/wp.1997.0009.

Comisión de Venecia. (2018). Informe sobre los límites a la reelección. Parte I-Presidentes. Estrasburgo: Comisión de Venecia.

Derpanopoulos, G., Frantz, E., Geddes, B. y Wright, J. (2016). Are coups good for democracy? Research and Politics, 3(1), 1-7. Disponible en: https://doi.org/10.1177/2053168016630837.

Farthing, L. (2020). In Bolivia, the right returns with a vengeance. NACLA Report on the Americas, 52 (1), 5-12. Disponible en: https://doi.org/10.1080/10714839.2020.1733217.

Fischer, T. (2018). Rechtsbeugung. En Beck'sche Kurzkommentare-Strafgesetzbuch (pp. 2542-2557). München: C.H. Beck.

Gandhi, J. (2008). Political Institutions under Dictatorship. Cambridge: Cambridge University Press. Disponible en: https://doi.org/10.1017/CBO9780511510090.

García, P. (2019). Los informes de la OEA condenaron a Evo al exilio. En M. Vaca (ed.). La Revolución de las Pititas (pp. 85-92). La Paz: Página Siete.

Geddes, B., Wright, J. y Frantz, E. (2014). Autocratic breakdown and regime transitions: A new data set. Perspectives on Politics, 12, 313-331. Disponible en: https://doi. org/10.1017/S1537592714000851.

González, E. (2001). En las tinieblas del Brumario: cuatro siglos de reflexión política sobre el golpe de Estado. Historia y Política, 5, 89-119.

Green, M. (2005). Legal revolutions: Six mistakes about discontinuity in the legal order. North Carolina Law Review, 83, 331-410.

Huntington, S. (1968). Political order in changing societies. New Haven: Yale University Press.

Isensee, J. (2013). Widerstandsrecht im Grundgesetz. En B. Enzmann (ed.). Handbuch Politische Gewalt (pp. 143-162). Wiesbaden: Springer Verlag. Disponible en: https://doi. org/10.1007/978-3-531-18958-1_7.

Kelsen, H. (1949). General theory of law and State. Cambridge: Harvard University Press.

Kotowski, C. (2009). Revolution-untangling alternative meanings. En D. Collier y J. Gerring (eds.). Concepts and method in social science: The tradition of Giovanni Sartori (pp. 203-240). London: Routledge. 
Landau, D. (2013). Abusive constitutionalism. UC Davis Law Review, 189, 1-58.

Lehoucq, F. (2020). Bolivia’s Citizen Revolt. Journal of Democracy, 3, 130-144. Disponible en: https://doi.org/10.1353/jod.2020.0050.

Levitsky, S. (2019). Na Bolívia houve golpe, diz autor de "Como as democracias morrem". $O$ Globo,12-11-2019. Disponible en: https://glo.bo/3iu4xZj.

Levitsky, S. y Loxton, J. (2013). Populism and competitive authoritarianism in the Andes. Democratization, 20 (1), 107-136. Disponible en: https://doi.org/10.1080/13510347.2 013.738864 .

Levitsky, S. y Murillo, M. V. (2019). The coup temptation. New York Times, 02-12-2019. Disponible en: https://nyti.ms/39LXyqJ.

Levitsky, S. y Way, L. (2015). The myth of democratic recession. Journal of Democracy, 26 (1), 45-58. Disponible en: https://doi.org/10.1353/jod.2015.0007.

Luttwak, E. (1969). Coup d'État-a practical handbook. New York: Alfred Knopf.

Maeda, K. (2010). Two modes of democratic breakdown: A competing risks analysis of democratic durability. The Journal of Politics, 72 (4), 1129-1143. Disponible en: https://doi. org/10.1017/S0022381610000575.

Mahmud, T. (1994). Jurisprudence of successful treason: Coup d'Etat and Common Law. Cornell International Law Journal, 49, 49-140.

Marinov, N. y Goemans, H. (2014). Coups and democracy. British Journal of Political Science, 44, 799-825. Disponible en: https://doi.org/10.1017/S0007123413000264.

Marshall, M. y Marshall, D. (2016). Coup D'État events, 1946-2015 Codebook. Vienna: Center for Systemic Peace. Disponible en: https://www.systemicpeace.org/inscr/CSPCoupsCodebook2015.pdf.

Marsteintredet, L. y Malamud, A. (2019). Coup with adjectives: Conceptual stretching or innovation in comparative research? Political Studies, 1-22. Disponible en: https://doi. org/10.1177/0032321719888857.

Martínez, R. (2014). Subtipos de golpes de Estado: transformaciones recientes de un concepto del siglo Xvir. Revista CIDOB d'Afers Internacionals, 108, 191-212.

Moore, C. (2010). Political and military coups. En J. Ishiyama y M. Breuning (eds.). 21st century political science: A reference handbook (pp. 124-132). Thousand Oaks: Sage. Disponible en: https://doi.org/10.4135/9781412979351.n15.

Morales, E. (2020). Volveremos y seremos millones. Buenos Aires: Ariel.

Natanson, J. (2019). Tres conclusiones sobre el golpe de Estado contra Evo Morales. Página 12. 12-11-2019. Disponible en: https://bit.ly/3qy1BxN.

Naudé, G. (1989). Considérations politiques sur les coups d'État. Paris: Les Editions de Paris.

Organization of American States (2019a). Statement of the OAS Electoral Observation Mission in Bolivia. Washington: Organization of American States. Disponible en: https://bit. ly/3sBQp5b.

Organization of American States (2019b). Durante el consejo permanente extraordinario convocado para estudiar la situación en Bolivia. Washington: Organization of American States. Disponible en: https://bit.ly/3nYdPhh.

O’Donnell, G. (1994). Delegative democracy. Journal of Democracy, 5, 55-69. Disponible en: https://doi.org/10.1353/jod.1994.0010. 
O’Donnell, G. (2008). Hacia un Estado de y para la democracia. En R. Mariani (ed.). Democracia/Estado/ciudadanía: Hacia un Estado de y para la democracia en América Latina (pp. 25-62). Lima: PNUD.

Peñaranda, R. (2019). La pacificación del país se operó tras bambalinas. En M. Vaca (ed.). La Revolución de las Pititas (pp. 235-248). La Paz: Página Siete.

Peralta, P. (2019). El TSE encaminó el proceso electoral al desastre. En M. Vaca (ed.). La Revolución de las Pititas (pp. 27-34). La Paz: Página Siete.

Pitts, B., Joyce, R., Sheptak, R., Hetherington, K., Castillo, M. y Ioris, R. (2016). 21st Century golpismo: A NACLA Roundtable. NACLA Report on the Americas, 48 (4), 334-345. Disponible en: https://doi.org/10.1080/10714839.2016.1258276.

Powell, J. y Thyne, C. (2011). Global instances of coups from 1950 to 2010: A new dataset. Journal of Peace Research, 48, 249-259. Disponible en: https://doi.org/10.1177/002 2343310397436.

Przeworski, A. (2013). Latin American Political Regimes in Comparative Perspective. En P. Kingstone y D. J. Yashar (eds.). Routledge Handbook of Latin American Politics (pp. 542-564). New York: Routledge.

Radbruch, G. (2003). Gesetzliches Unrecht und übergesetzliches Recht. En G. Radbruch (ed.). Rechtsphilosophie (pp. 211-219). Heidelberg: C.F. Müller.

Rapoport, D. C. (1966). Coup d'État: The view of the men firing pistols. En C. Friedrich (ed.). Revolution (pp. 53-74). New York: Atherton Press. Disponible en: https://doi. org/10.4324/9781315128610-4.

Romero, P. (2019). Motín: el día en que los policías se reconciliaron con el pueblo. En M. Vaca (ed.). La Revolución de las Pititas (pp. 77-84). La Paz: Página Siete.

Sampford, C. (1989). Coups d'Etat and Law. Bulletin of Australian Society of Legal Philosophy. 13, 253-286 Disponible en: https://bit.ly/3901HIE.

Scheppele, K. (2018). Autocratic Legalism. University of Chicago Law Review, 85, 545-583.

Shifter, M. (2019). En términos muy técnicos lo de Bolivia es un golpe. La República, 17-112019. Disponible en: https://bit.ly/2KuvSht.

Snyder, R. (2006). Beyond electoral authoritarianism: The spectrum of nondemocratic regimes. En A. Schedler (ed.). Electoral authoritarianism: the dynamics of unfree competition (pp. 219-231). Colorado: Lynne Rienner.

Stone-Sweet, A. (2007). The juridical coup d'etat and the problem of authority. German Law Journal, 8, 915-927. Disponible en: https://doi.org/10.1017/S2071832200006064.

Svolik, M. (2012). The politics of authoritarian rule. Cambridge: Cambridge University Press. Disponible en: https://doi.org/10.1017/CBO9781139176040.

Svolik, M. (2015). Which democracies will last? Coups, incumbent takeovers, and the dynamic of democratic consolidation. British Journal of Political Science, 45, 715-738. Disponible en: https://doi.org/10.1017/S0007123413000550.

Thyne, C. y Powell, J. (2016). Coup d'Etat or Coup d'Autocracy? How Coups impact democratization 1950-2008. Foreign Policy Analysis, 12, 192-213.

Unión Europea (2019). Bolivia 2019. Informe final: elecciones generales 20 de octubre de 2019. Unión Europea, Misión de Expertos Electorales. Disponible en: https://bit.ly/2NpdbNz.

Varol, O. O. (2012). The democratic coup d'état. Harvard International Law Journal, 53, 291-356. 
Viciano, P. y Moreno, G. (2018). Cuando los jueces declaran inconstitucional la constitución: la reelección presidencial en América Latina a la luz de las últimas decisiones de las Cortes Constitucionales. Anuario Iberoamericano de Justicia Constitucional, 22, 165-198. Disponible en: https://doi.org/10.18042/cepc/aijc.22.06.

Wolff, J. (2020). The turbulent end of an era in Bolivia: Contested elections, the ouster of Evo Morales, and the beginning of a transition towards an uncertain future. Revista de Ciencia Politica, 40, 163-186. Disponible en: http://dx.doi.org/10.4067/ S0718-090X2020005000105. 